[Technical Paper]

\title{
Relationship between the Conductivity of Isotropic Conductive Adhesives (ICAs) and the Lubricant Coated on Silver Filler Particles
}

\author{
Shigeru Kohinata*, Akari Terao*, Yosihiko Shiraki*, Masahiro Inoue**, and Keisuke Uenishi* \\ * Osaka University Department of Management of Industry Technology Graduate School Engineering \\ **Gunma University Advanced Scientific Research Leaders Development Unit
}

(Received September 9, 2013; accepted December 12, 2013)

\begin{abstract}
We investigated the relationship between the conductivity of isotropic conductive adhesives (ICAs) and silver (Ag) particles (filler) that are coated with different lubricants; high molecular weight fatty acid. The components of the ICAs are organic epoxy binder and silver filler. The conductivity of the ICAs was measured by a milliohm tester and the electron charge between silver particles was determined by powder charge amount measurements. The conductivity of ICAs differs depending on the kind of lubricant used, and there is a possible correlation between conductivity and the charge amount of silver particle in the samples. These results suggest that the conductivity of ICAs is not only a result of connections between the silver particles, but also of some interaction between the lubricants and silver particles. The silver filler particles in the ICAs appear to function as micro-capacitors in the cured state.
\end{abstract}

Keywords: ICA, Conductivity, Fatty Acid, Lubricant, Silver Particle, Filler, Micro-capacitor, Curing

\section{Introduction}

ICAs are a fundamental material for substrates and semiconductors, and have many advantageous properties compared with solder (including lead-free solder), such as low temperature bonding, light weight, and stress relief.

ICAs are made from silver particles, thermoset resin binder, and lubricants which cover the particles. The electrical and thermal conductivity characteristics of ICAs depend on the silver particle content. The heat resistance and adhesion strength arise from the organic epoxy binder, which is formed in an irreversible thermal reaction.

In recent years, ICAs have attracted attention as a solder replacement that is safe for the environment and humans.[1] However, the physical levels of electric and thermal conductivity required for solders have not yet been reached with ICAs. Furthermore, some parts of the mechanism of ICAs are not yet clear. As one example, it was thought that contact between silver particles increased as their density increased due to contraction accompanying the curing of the binder, and the electrical connection until now. However, it has turned out that the contraction and conductive revelation during curing is not necessarily in agreement.

The chemical reaction accompanying curing is suggested to affect the electric conductivity of an ICA in addition to the physical reaction of the accompanying contraction. Even so, the conductance of ICA changes sharply if only the lubricant is changed. Thus, something that occurs in the curing between the resin binder, $\mathrm{Ag}$ powder, and lubricant appears to be related to the change in conductance. Therefore, we investigated the relationship between different kinds of fatty acids (lubricants) that are used to cover the silver particles, and the direct current resistivity of ICAs. In our experiments, the binder is fixed, and the type and content of lubricant used for coating the silver particles are changed.

Epoxy resin is used as the main binder and a phenol resin is employed as a curing agent for the binder. Flaky silver particles are used as the filler. Samples are prepared in one step by curing the ICAs, which is similar to the industrial production of ICA pastes. [2] In addition, the powder charge amount of silver particles is determined from powder charge measurements and the quantity of 
lubricant coating the silver particles.

We found that the conductivity of cured ICAs can be affected by a comparatively small amount of lubricant. In addition, the conductivity of cured ICAs decreases with powder charge. It was seen that the conductance values of each ICA paste do not always depend on the boiling point of the lubricant. It seems that the lubricant coated on the surface of the silver particles not only contributes to their dispersion but also reacts with the binder. This in turn affects the conductivity of the cured ICAs. The lubricant, which is an insulating organic material, tends to increase the mutual contact resistance of the silver particles. It is thought the ICAs behave similarly to a micro-capacitor when considering the silver particles, binder and lubricant.[3]

\section{Experimental}

\subsection{Sample preparation}

A bisphenol A-type epoxy (YD-980, Mitsubishi Kagaku Media Co., Ltd) was used as the main binder. The curing agent was novolac phenol resin (HPL-3, Sumitomo Bakelite. Co., Ltd) with a mixing ratio of resin and curing agent equals $100 / 50$ by weight percent. Figure 1 shows an overview of the curing of the epoxy binder. In this figure, $\mathrm{A}$ is the epoxy resin, $\mathrm{B}$ is the novolac phenol resin (curing agent) and $\mathrm{C}$ is the cured epoxy binder. The epoxy resin binder forms a three-dimensional structure by ring-opening polymerization. No catalytic agent to accelerate the binder reaction was used in our experiments. [4]

Silver particle flakes (Metaro Co. Ltd) with an average diameter of $5 \mu \mathrm{m}$ and thickness of $1 \mu \mathrm{m}$ were used as filler particles. Lubricant coatings using the fatty acids listed in Table 1 were formed by the mechano-fusion method. The physical properties of the lubricants are presented in Table 2.

Three types of ICA with silver weight ratios of $79 \mathrm{wt} \%, 81$ $\mathrm{wt} \%$ and $85 \mathrm{wt} \%$ were prepared. ICA pastes were prepared by mixing the above-mentioned materials using a triple roll mill (Inoue Co. Ltd). To lower the viscosity of the ICA pastes, butyl carbitol (a nonreactive diluent, Kanto Chemical

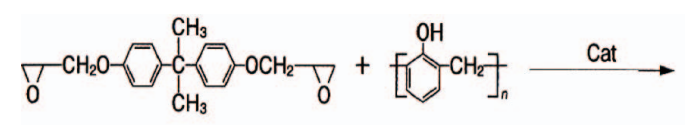

A

B

C

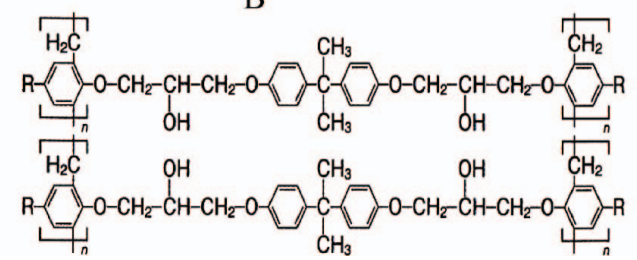

Fig. 1 Curing of ICA Binder.

Table 2 Physical properties of lubricants.

\begin{tabular}{c|c|c|c|c}
\hline No & $\begin{array}{c}\text { mol, mass } \\
\mathrm{g} / \mathrm{mol}\end{array}$ & $\begin{array}{c}\text { melting } \\
\text { point }^{\circ} \mathrm{C}\end{array}$ & $\begin{array}{c}\text { boiling } \\
\text { point }{ }^{\circ} \mathrm{C}\end{array}$ & $\begin{array}{c}\text { specific } \\
\text { gravity }\end{array}$ \\
\hline (1) & 200.32 & 44.8 & 298.9 & 0.883 \\
\hline (2) & 284.48 & 70.5 & 283 & 0.847 \\
\hline (3) & 228.37 & 54.1 & 240.3 & 0.8622 \\
\hline (4) & 282.47 & 16.2 & 223 & 0.89 \\
\hline (5) & 182.17 & 95 & 296 & $1.489^{*}$ \\
\hline (6) & 256.42 & 62.65 & 351 & 0.853 \\
\hline (7) & 340.58 & 80.02 & 306 & - \\
\hline (9) & - & 95 & 296 & $1.489^{*}$ \\
\hline (10 & - & 44.8 & 298.9 & $0.883^{*}$ \\
\hline
\end{tabular}

*Partly mixture

Table 1 Lubricants used to coat silver particles.

\begin{tabular}{|c|c|c|c|}
\hline No & Fatty Acid Type & \multicolumn{2}{|l|}{ Formula } \\
\hline (1) & Lauric acid & \multicolumn{2}{|l|}{$\mathrm{CH}_{3}\left(\mathrm{CH}_{2}\right)_{10} \mathrm{COOH}$} \\
\hline (2) & Stearic acid & \multicolumn{2}{|l|}{$\mathrm{CH}_{3}\left(\mathrm{CH}_{2}\right)_{16} \mathrm{COOH}$} \\
\hline (3) & Myristic acid & \multicolumn{2}{|l|}{$\mathrm{CH}_{3}\left(\mathrm{CH}_{2}\right)_{12} \mathrm{COOH}$} \\
\hline (4) & Oleic acid & \multicolumn{2}{|c|}{$\mathrm{CH}_{3}\left(\mathrm{CH}_{2}\right)_{7} \mathrm{COOH}=\mathrm{CH}_{3}\left(\mathrm{CH}_{2}\right)_{7} \mathrm{COOH}$} \\
\hline (5) & Sorbitol/Oleic acid & $\left(\mathrm{CH}_{2} \mathrm{OH}\right) \mathrm{O}_{4} \mathrm{H}_{8}$ & $\mathrm{CH}_{3}\left(\mathrm{CH}_{2}\right)_{7} \mathrm{COOH}=\mathrm{CH}_{3}\left(\mathrm{CH}_{2}\right)_{7} \mathrm{COOH}$ \\
\hline (6) & Palmitic acid & \multicolumn{2}{|l|}{$\mathrm{CH}_{3}\left(\mathrm{CH}_{2}\right)_{14} \mathrm{COOH}$} \\
\hline (7) & Behenic acid & \multicolumn{2}{|l|}{$\mathrm{CH}_{3}\left(\mathrm{CH}_{2}\right)_{20} \mathrm{COOH}$} \\
\hline (9) & Sorbitol/Stearic acid & $\left(\mathrm{CH}_{2} \mathrm{OH}\right) \mathrm{O}_{4} \mathrm{H}_{8}$ & $\mathrm{CH}_{3}\left(\mathrm{CH}_{2}\right)_{16} \mathrm{COOH}$ \\
\hline (10) & Lauric acid/Stearic acid & $\mathrm{CH}_{3}\left(\mathrm{CH}_{2}\right)_{10} \mathrm{COOH}$ & $\mathrm{CH}_{3}\left(\mathrm{CH}_{2}\right)_{16} \mathrm{COOH}$ \\
\hline
\end{tabular}

*Fatty acid type: kinds of lubricant 
Co., Ltd) was added.

\subsection{Measurements}

The thermal properties and curing behavior of the ICAs were measured by thermo-gravimetric-differential thermal analysis (Model: 6300 SII Co., Ltd) in an air atmosphere. The condition of each lubricant was analyzed by Fourier transform-infrared (FT-IR) spectroscopy (IR-P-21, Shimadzu Co., Ltd).

To measure the resistivity, the ICA pastes were printed on alumina substrates. The printed paste was $2 \mathrm{~mm}$ square and $20 \mu \mathrm{m}$ thick. Before and after curing under various conditions, the resistivity was measured by the four-point probe method using a Milliohm HiTester (3540 Hioki Co. Ltd) at room temperature. The amount of charge between filler particles was measured in the blow-off mode using a blow-off charge measurement apparatus (TB-20, Toshiba Chemical Co. Ltd.). To measure their adhesion to substrates, the ICA pastes were printed and cured on $1.5 \mathrm{~mm}^{2}$ Si integrated circuit chips. Then, the adhesion strength in the horizontal direction was measured using a push-pull gauge tester at room temperature.

\section{Results and Discussion}

The ICAs were made to binder $\mathrm{A} / \mathrm{B}=100 / 50(\mathrm{w} \%)$, and a silver particle/binder ratio of $35 / 65$ to $75 / 25$ by weight.

The flaky silver particles used had an average particle diameter of about $5 \mu \mathrm{m}$. (Fukuda Metal Co. Ltd.). The kind of fatty acid of the lubricant is unknown.

Figure 2 shows the effect of the weight ratio of silver filler on the adhesion strength and resistivity of the ICAs after curing. With increasing volume fraction of silver

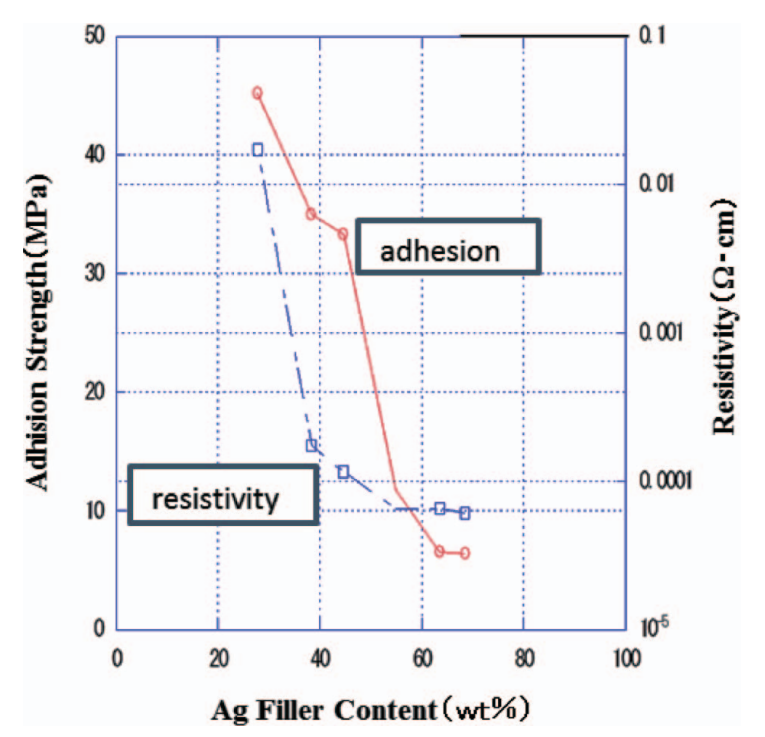

Fig. 2 Adhesion strength and resistivity versus the silver filler content of ICAs. filler, the resistivity of the ICAs decreased. Above a weight ratio of silver filler of $65 \mathrm{wt} \%$, the resistivity hardly changed. It seems the percolation threshold concentration of the present silver powder is $65 \mathrm{wt} \%$ and the resistivity of ICAs with more silver filler will exhibit almost the same resistivity as that of ICAs with $65 \mathrm{wt} \%$ silver.[5]

Figure 3 shows changes in the ring-opening polymerization ratio of the epoxy radical of the ICAs during curing at $125^{\circ} \mathrm{C}$ and $150^{\circ} \mathrm{C}$, measured by FT-IR spectroscopy. Because the polymerization ratio was almost constant after heating at $125^{\circ} \mathrm{C}$ and $150^{\circ} \mathrm{C}$ for more than 30 minutes, it appears that the curing reaction stops after 30 minutes in each temperature range.

$150^{\circ} \mathrm{C}$ was selected as the curing condition in this research.

Figures 4, 5, and 6 show the resistivity of the ICAs cured at higher temperatures of $150^{\circ} \mathrm{C}, 220^{\circ} \mathrm{C}$, and $350^{\circ} \mathrm{C}$. Most of these samples exhibited lower resistivity than those cured at $150^{\circ} \mathrm{C}$. These results may conflict with the observations that the epoxy resin is completely cured at $150^{\circ} \mathrm{C}$

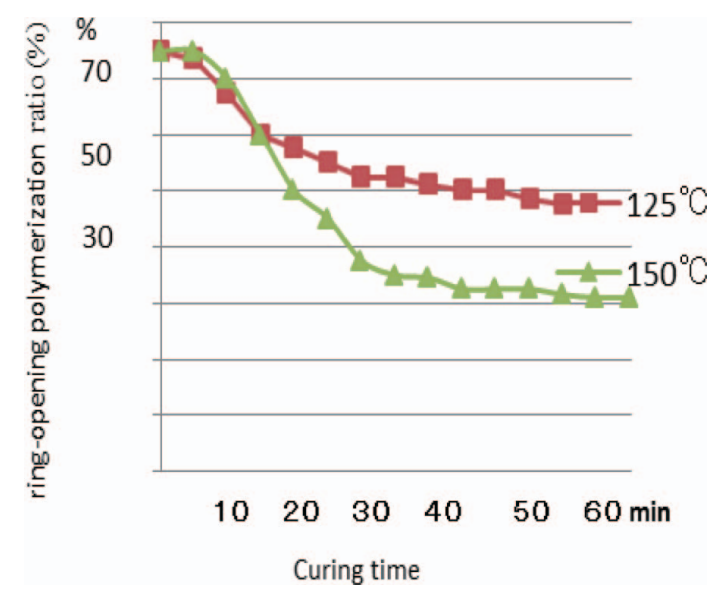

Fig. 3 Ring-opening polymerization ratio of epoxy binder during curing.

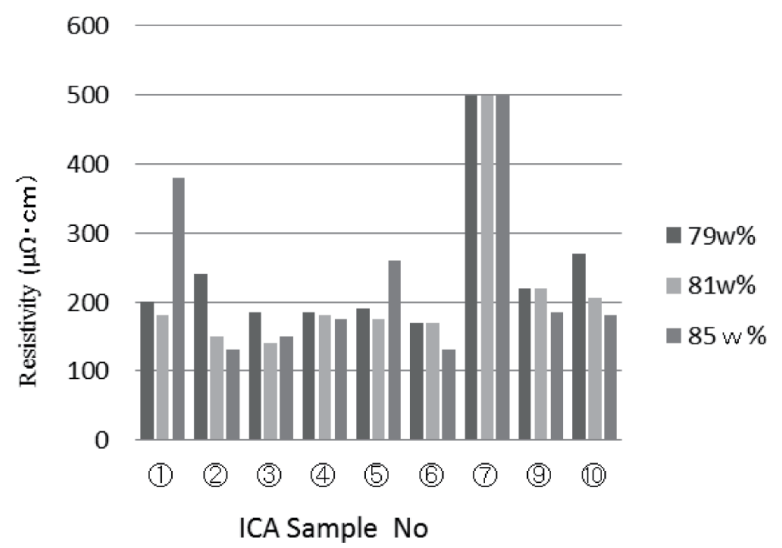

Fig. 4 Resistivity vs silver Content and change lubricant of ICA (1) $150^{\circ} \mathrm{C} 30 \mathrm{~min}$ Cure. 


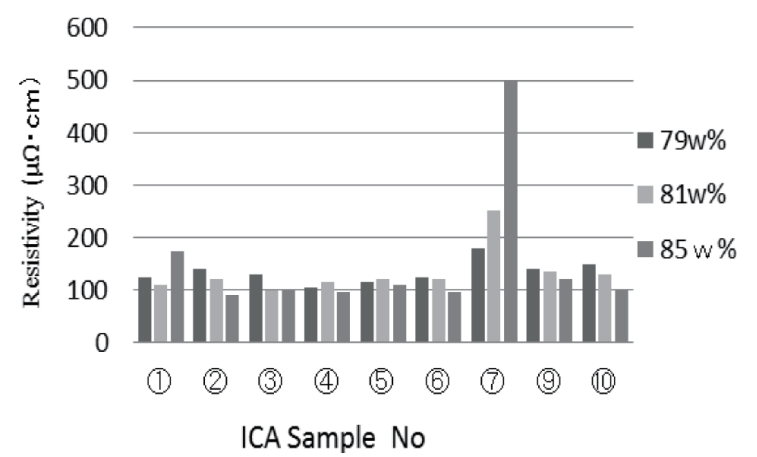

Fig. 5 Resistivity vs silver Content and change lubricant of ICA (2) $220^{\circ} \mathrm{C} 30 \mathrm{~min}$ Cure.

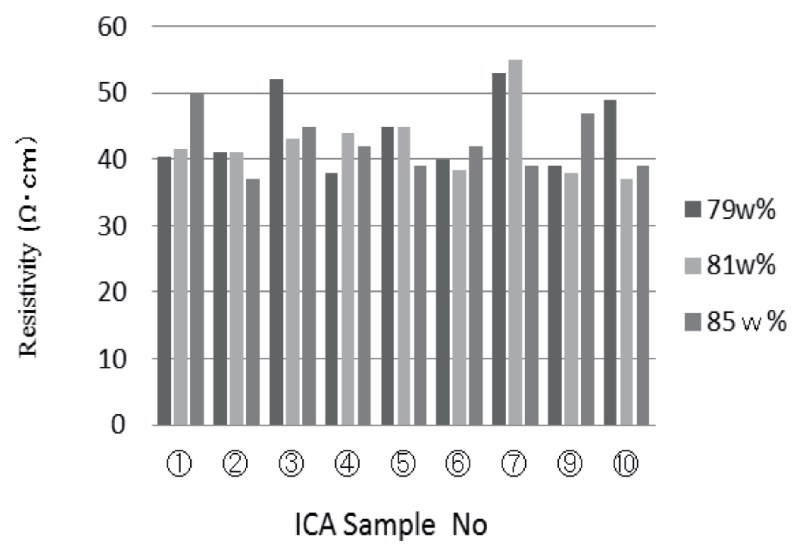

Fig. 6 Resistivity vs silver Content and change lubricant of ICA (3) $350^{\circ} \mathrm{C} 30 \mathrm{~min}$ Cure.

and that the boiling points of the lubricants other than oleic acid are higher than $220^{\circ} \mathrm{C}$. Because few cracks and voids were observed in the cured ICAs, their influence on resistivity can be neglected.[6] Instead, these findings may be explained by the shrinkage and internal stress of the binder. That is, curing at higher temperature induces larger shrinkage and internal stress of the binder, which decreases the inter particle distance.

Consequently, the contact area between silver particles increases, as shown in the schematic illustration in Fig. 7. The ICA with behenic acid (Sample 7), whose resistivity hardly changed with curing at $220^{\circ} \mathrm{C}$, exhibited lower resistivity with curing at $350^{\circ} \mathrm{C}$. Almost all of the ICAs exhibited similar resistivity because the boiling points of all of the lubricants were less than $350^{\circ} \mathrm{C}$. Overall, it can be concluded that the lubricant has some effect on the resistivity of ICAs at $150^{\circ} \mathrm{C}$ and $220^{\circ} \mathrm{C}$. To examine the effect of the lubricant, the amount of charge between silver fillers with various lubricants was measured.[7]

To measure the amount of charge in a powder, a sample is separated by flowing gaseous nitrogen through a wire netting that is attached to a metal container holding a standard powder (toner powder), which is commensurate with

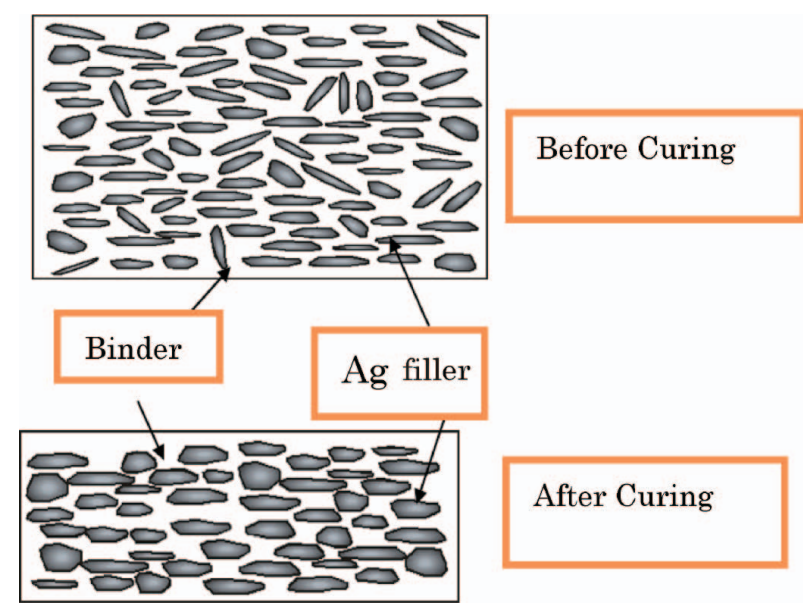

Fig. 7 The formation of an ICA during curing.

Table 3 Powder charge and amount of lubricant adhering to the particles for the silver particles coated with various lubricants.

\begin{tabular}{c|c|c}
\hline $\begin{array}{c}\text { Silver particle } \\
\text { Sample No }\end{array}$ & $\begin{array}{c}\text { Powder Charge } \\
\text { Amount }(\mu \mathrm{C} / g)\end{array}$ & $\begin{array}{c}\text { adherent } \\
\text { quantity W\% }\end{array}$ \\
\hline$(1)$ & 0.983 & 0.57 \\
\hline$(2)$ & 1.058 & 0.09 \\
\hline$(3)$ & 2.022 & 0.05 \\
\hline$(4)$ & 1.296 & 0.05 \\
\hline 5 & 1.599 & 0.04 \\
\hline 6 & 2.079 & 0.04 \\
\hline$(7)$ & 5.152 & 0.89 \\
\hline$(9)$ & 1.981 & 0.04 \\
\hline (1) & 2.092 & 0.35 \\
\hline
\end{tabular}

$100 \mathrm{mg}$ of silver particles (known as the blow-off method). The opposite electrification is the equivalent of the silver powder being carried away by the toner powder that was left in the metal container. The electrification quantity $(|\mathrm{Q}|)$ can be estimated by measuring the voltage change (V) on both edges in the condenser (capacity $\mathrm{C}$ ) that is connected with the container because of its charge $|\mathrm{Q}|=\mathrm{CV}(\mu \mathrm{C} / \mathrm{g})$.

Table 3 shows the amount of charge between lubricantcoated silver filler particles. The weight fraction of lubricant adhered to the silver filler surface is also shown. Particles with behenic acid (7) exhibited the highest charge quantities of the ICAs. Lauric acid, behenic acid, and the mixture of lauric and stearic acids (samples 1, 7 and 10, respectively) were more adhesive to silver particles than the other lubricants.

Comparing the amount of charge and resistivity of the ICAs suggests that they are correlated. Considering that a higher weight fraction of filler particles did not always lead 
to higher conductivity, electrical conduction seems to occur not only through the contact area of the filler particles but also through the lubricant and binder between separated particles. It is considered that separated particles play a role in conduction by acting like micro-capacitors in the cured ICAs. The lubricants coating the filler particles may control not only the dispersion of filler particles but also the charge properties between them. We measured only direct-current resistance in this research so we cannot divide the impedance and resistance. Even when the silver particle contents, the distance between particles, and the curing conditions of the ICAs are the same, the resistivity of the ICAs changes with the differences in the kind of lubricants.

If the electric charge for the silver particle moves, the inherent resistivity of kind of lubricant is related. It is thought to behave like a capacitor between the silver particles, lubricants, and the resin binder.

\section{Conclusion}

We investigated the relationship between the resistivity and the lubricant used in ICAs composed of epoxy resin and silver filler.

Our conclusions are as follows:

1. The influence of the filler weight fraction on resistivity varies up to $65 \mathrm{wt} \%$. Thus the percolation threshold concentration of the present silver powder was determined to be $65 \mathrm{wt} \%$. By investigating the changes in the ring-opening polymerization ratio of the epoxy radicals of the ICAs during curing, curing conditions of heating at $150^{\circ} \mathrm{C}$ for 30 minutes were selected.

2. The resistivity of the ICAs depends on the lubricant coating the filler particle when the binder and volume fraction of filler particles are identical. The ICA with behenic acid lubricant exhibited the highest resistivity of the samples, and those with myristic and palmitic acids exhibited the lowest.

3. Combined with the result that a higher weight fraction of filler did not always lead to higher conductivity, electrical conduction appears to occur not only through the contact area of the filler particles but also through the binder and lubricant between sepa- rated particles. It is considered that the separated particles have a role in conduction by acting as a micro-capacitors in the cured ICAs. The lubricants coated on the filler particles may control not only their dispersion but also the movement of charge between filler particles.

\section{References}

[1] K. Sasaki, "Isotropic Conductive Adhesive Science and Industrial Material,” Japanese materials Science Society, Vol. 41, No. 2, pp. 63-66, 2004.

[2] S. Kohinata, "The Basics on the Isotropic Conductive Adhesive Part 1,” Journal of The Japan Institute of Electronics Packaging, Vol. 9, No. 6, pp. 495-505, 2006.

[3] M. Inoue, "The Electricity and the Heat Transportproperty of Particle Distributed Network Polymer," Network Polymer, Vol. 32, No. 4, pp. 210-216, 2011.

[4] Y. Li, K-S. Moon, H. Li, and C. P. Wong, "Development of isotropic conductive adhesives with improved conductivity," Proc. 9th International Symposium on Advanced Packaging Materials: Processes, Properties and Interfaces, pp. 1-6, 2004.

[5] S. Nakamura, "The Percolation Phenomenon at the Polymer Materials," The American Institute of Electrical Engineers Magazine, American Electrochemical Society, Vol. 25, No. 3, pp. 142-147, 2004.

[6] L. Li, C. Lizzul, H. Kim, I. Sacolick, and J. E. Morris, "Electrical, Structural and Processing Properties of Electrically Conductive Adhesives,” IEEE Trans. on Components, Hybrids, and Manufacturing Technology, Vol. 16, No. 8, pp. 843-851, 1993.

[7] D. Lu and C. P. Wong, "Effects of shrinkage on conductivity of isotropic conductive adhesives," International journal of Adhesion and Adhesives, Vol. 20, No. 3, pp. 189-193, 2000.

\section{Shigeru Kohinata \\ Akari Terao \\ Yosihiko Shiraki \\ Masahiro Inoue \\ Keisuke Uenishi}

